\title{
CONJOINT MARITAL THERAPY IN THE SERVICES
}

\author{
MAJOR J. R. BIRD, M.B., B.S., M.R.C.Psych., D.P.M., R.A.M.C. \\ Royal Victoria Hospital, Netley
}

\begin{abstract}
SUMMARY: Marital therapy as a needed and worthwhile approach to disordered marriages is discussed. A conjoint treatment method is described in detail. Aspects of the service setting of particular significance to the treatment are stressed.
\end{abstract}

\section{Introduction}

Treating a married couple, like public speaking, is not easy. None the less, in the past twenty years, marital therapy has, as Gurman (1973a) states, "come of age as a viable psychotherapeutic endeavour". How it may be applied with marital problems is a matter of individual skill and learning.

A behaviourist approach is favoured by Lieberman (1970), Crowe (1973) and Bancroft (1975), whilst others, such as Linden et al (1968) and Gurman (1971) describe a group method. Indeed, group treatment in a military setting, has been specifically described by Hartog (1966) and Cook (1964), though neither focused on its application to marital problems.

In fact, a survey of the literature reveals no paper based on marital treatment in the services. Though Frances and Gale (1973) highlight aspects of family structure and treatment in the military and Peck and Schroeder (1976), in an illuminating article, discuss the difficulties of psychotherapy with a family whilst the father is absent on military duty.

The need for more help with disturbed marriages was stressed by Wawman (1973) and the Report of the Army Welfare Inquiry Committee (1976); whilst the extent of marital stress, contributory factors and difficulties in diagnosis were noted in an earlier paper by Bird (1977). At the present time, the emphasis in the services, particularly overseas, is to rely on the SSAFA social workers and unit chaplains, as the main helpers in the marital area. It may be that the demand on these lay figures represents all too often an excessive shifting of responsibility on the part of the medical profession. Whilst Goldberg et al (1968) comment on the great value of social worker help to the family practice, it clearly needs to be a two way business and the social worker should supplement and not supplant the doctor. Conjoint marital therapy, an approach in which both partners are seen together, can be used by service doctors and other workers in dealing with marital problems. One refinement would be to have co-therapists. Here the doctor and social worker could function together or a registered mental nurse could fill one role, an approach advocated by Shapiro (1975).

Alternatively, a three person setting, with one therapist, may be chosen and might well be the most logical arrangement in the average service setting. The various advantages and disadvantages of the "single therapist" approach are mentioned by Dicks and Stephens (1974), Greene and Solomon (1963), whilst Gurman $(1973 \mathrm{~b})$, assessing the effectiveness of marital therapy, notes only a slightly better therapeutic result with the co-therapist as opposed to single therapist method, giving improvement rates of 73 per cent and 65 per cent respectively. 


\section{Conjoint treatment}

\section{Aim}

The aim, as Sager (1964) observed, is to use the inter-action between the couple as a medium for change. The chosen adaptive behaviour by the marital partners is on display, open to confrontation and interpretation, with hopefully increasing insight.

It is the pathological social unit, the marriage, which is the focus of treatment and not the individuals. This means that the approach is consistently directed to a clarification of present problems, by increasing communication between the couple. Seeing the couple together heightens mutual awareness, facilitates change at a pace with which the partners can cope and provides a setting in which the efforts to work through problems can be discussed.

Conjoint meetings avoid the distorted account that one partner alone might bring and is an ideal treatment for patients who would be unable to cope with individual treatment, points noted by Kohn (1962), and Frankel (1977).

A further aim, is to bring together in a non-judgemental, non-critical atmosphere, a couple who have moved apart and who may be engaged as Sager (1967) pithily observed, "in the first co-operative venture' in which they have participated for a long time".

\section{Method}

Since one partner so frequently presents alone, history taking may initially be done individually, but as soon as possible a joint interview is arranged. Here the therapist obtains a joint account, observes the couple's behaviour together and by his impartial attitude sets the scene for his acceptance by the couple.

It is rare not to feel the balance of blame lies with one partner, indeed such a judgement may be invited. Equally rarely is this the full truth. Unwillingness to pair with either husband or wife and an insistence on seeing the marital problem as shared, increases not only the confidence of the blamed partner, but also the other. The assessment interviews are used to formulate an understanding of the underlying marital dynamics, to assess suitability and desire for treatment and, if agreed, to discuss the practical details. Time spent on spatio-temporal arrangements is never wasted. Agreement on where and when to meet, and for how many sessions, gives a structure to the treatment with which patients and therapists can identify. Weekly one hour sessions, on the same day and at the same time are best. Acceptance of this implies a three way commitment and conveys a willingness on all sides to invest time and effort in a therapeutic endeavour.

At the same time, with a structured treatment programme, changes can be clearly identified as a result of the therapy and within the couple. The aim all the time, is to give the treatment an identifiable boundary, something that has become blurred in the marital relationship. This is the very basis of a working alliance, the reality orientated treatment agreement, without which no therapy can prosper.

\section{The service setting}

Just as the working alliance is reality based, so is the fact that treatment develops within the framework of the service setting. Frequently there are initial 
and very real problems in bringing a couple together, owing to resistance by either husband or wife. The soldier may feel his career is threatened, promotion put at risk, or his domestic life the focus of military attention. Additionally, he may feel constrained by a request to attend, seeing it as an order perhaps, and whilst maintaining an eminently correct and respectful attitude, brings solely an outer shell.

Either partner may experience ambivalence towards what is essentially a reflective procedure and find the change from an acting out relationship to one of communication, difficult.

The realities of rank and authority must have an effect. In the hierarchial structure of the military, attitudes are formed, boundaries are well defined and everyone knows their exact place. The doctor, the padre, indeed the social worker, have a rank or position which must influence how they are approached, viewed and used by client or patient. It may be, that as representatives of the establishment they can only be challenged or conversely never challenged at all. What may prove difficult to demonstrate, is that the therapist can cope with the issue of rank, neither emphasising nor belittling the difference. Trust and confidence are always necessary, but particularly so in a psychotherapeutic treatment setting. It develops from the therapist's manner, approach and respectful acceptance of his patients. Woodhouse (1977), writing on how some patients attempt actively to exclude family doctors from their personal problems makes a point that is entirely valid to service life. Overseas, such traditionally separate and private organisations as the Family Planning and Marriage Guidance Clinics do not exist. The family doctor is then, as Chester (1973) stressed, the first helper involved.

His reaction to a presented problem, indeed his willingness to diagnose marital stress, must have an influence on whether or not a couple will contemplate treatment. Quite possibly one of the three people involved would rather leave the whole mess undisturbed, and it requires only one, to sabotage the efforts of the other.

This could lead to an inappropriate approach along lines of environmental manipulation. The service doctor, has considerable power and influence in this area. Changes in housing, posting, duties and leave are all immediate examples, whilst the ready access to social work support, specialist opinion, indeed hospitalisation, compare most favourably with civilian practice. Additionally, fostering, home visiting and neighbour help are traditional areas of unit support.

The need for any of these, may reflect the need for marital therapy. The risk is that situational change may be seen as all that is needed, in all cases.

A further aspect of service life, relevant to a treatment that requires regular attendance, is whether or not units will allow this. The service doctor has again an advantage over his civilian counterpart. He may. well know unit officers personally, but will in any case have ready access to them. He will know the type of unit, soldier's job, projected moves, exercises and so forth, or can find out. The soldier, by the very nature of service life, cannot just take time off, but it has certainly been the writer's experience that most units make every effort to free soldiers to attend treatments. 
In any event, brief marital therapy, with a limited number of sessions, is as Gill and Temperley (1974) have shown, very worthwhile.

\section{Transference and counter transference}

It will be clear from what has already been written, that a conjoint approach is demanding and the inevitability of its being structured in a service setting, produces additional unique difficulties. It is tempting to avoid complicating the issue by highlighting aspects of transference and counter transference. Both are, concepts that prove difficult to fully grasp and understand. However, two factors make knowledge, appreciation and use of these concepts essential. First, transference, counter transference and interpretations are the very stuff of a psychotherapeutic approach, representing the significant difference from a counselling method. Secondly, they cannot realistically be ignored, because they must be operative in such a treatment setting.

Very loosely defined, transference represents the patient's emotional feelings experienced and expressed towards the therapist. It develops both as a result of previous emotional interactions with significant persons in the patient's life, frequently parents, and as a displacement from meaningful figures in current life.

Counter transference implies feelings experienced by the therapist towards his patient and are evoked by the patient's transference, behaviour and the therapist's own unconscious attitude.

Whilst Skynner (1969), advocates a directive therapist technique with minimal attention to the transference, this seems to have a serious drawback with service patients. They expect a directive approach, instruction, exhortation, indeed judgement. Such whilst meaningful and relevant to military affairs is likely to be resented in personal and private life where being told what to do is certainly counter productive.

Accepting the couple's transferred feelings of whatever sort, dislike, anger, rebellion, dependency, affection and so forth demonstrates an ability to accept the couple. Clearly this increases the therapist's understanding of how they also react to each other. Interpreting the transference, heightens the partners' awareness of how they react in relationships and how patterns and aspects of behaviour have developed.

\section{Example 1}

Sergeant and Mrs. D, aged 28 and 25 years, both eldest children, presented with dyspareunia. Intercourse had been successful before they married 2 years earlier. Each had experienced their parents as hypercritical, restrictive and impossible to satisfy. As a result, they experienced both resentment and helplessness, expecting to fail and in some measure obtaining satisfaction from the effects of failure on their parents.

In therapy, it was clear they were perpetuating this approach in the sexual area of the marriage. It was possible to interpret this state of affairs in the transference.

They reported that once a week, on the night before a treatment session, they 
invariably attempted to make love, but failed. This was interesting because before therapy they had avoided intercourse for several months.

It was thus easy to point out that they were treating me like a parent who was demanding successful intercourse from them. They saw me as critical and needing to be placated. Their response to these feelings was to react as they had so often with their own parents, attempt something-intercourse-but then fail. Perhaps, their resentment ensured that lovemaking would fail.

This led them both to admit that they experienced real satisfaction from frustrating their partner and had indeed discussed how they actively enjoyed frustrating me. Neither had seen this in relationship to their sexual lives before and were able to question and ultimately change this pattern of behaviour.

\section{Example 2}

A couple, both employed, had been very involved and working in the sessions from the beginning. However, for some weeks they had come late, spoke little and even "forgot" sessions. The change in them was quite remarkable. The reason became clear when both talked about resentment they experienced at senior work colleagues, how they had tried so hard but seemed unable to get promotion, acknowledgement and so forth.

In the transference they saw me as the "boss". It was possible to interpret this by showing them how they treated me as the "boss", with the knowledge and the capacity to reward. But all I seemed to do was to sit silent, frustrating them and giving little in return for what they offered me. At the same time though they obviously felt resentful and angry, they were frightened to express this directly and showed it by coming late, "forgetting" sessions and being silent.

Since poor communication between them had been a major presented marital problem perhaps expressing what they really felt might help. They were able to verbalise anger towards me, find they could still be accepted and as a result became more open and honest with each other.

It is not possible to cover either transference or counter transference in depth in one paper, but it needs to be stressed that a therapist must experience "feelings" about his patients, some rational, others irrational. These will influence his approach, attitude and handling of the treatment. Such feelings must be scrutinised constantly, ideally by treating cases under supervision, or with more difficulty, by personal introspection. A distinct advantage of having a co-therapist, is the opportunity for mutual evaluation of counter transference.

\section{Communication and interpretation}

Watson (1963), makes the point that conjoint marital therapy, "improves the capacity to communicate rationally and resolve mutual problems more objectively". The implication is; that if a couple can talk together in a meaningful way, explore their relationship together and increase mutual understanding and awareness, then they are in a better position to change unsatisfactory patterns of behaviour. Therapy is about getting the partners to talk to each other, not to the therapist. This is best accomplished by keeping questions to a minimum and using interjections to focus the couple on shared difficulties of communication if silences 
are prolonged. Talking must be clearly understood to be the work of the couple. The therapist's role is to facilitate understanding and hopefully change by interpreting what he observes and hears.

To avoid pairing or confronting one partner alone, joint interpretations are used. Besides the obvious advantage of not picking on one partner, it maintains the focus on the relationship problems and not individual psychopathology.

Transference interpretation was shown in Example 2. It seeks to point out, as Teruel (1966) has observed, what is acted out in the session.

The joint interpretation, is a confronting of the couple with what seems to be the meaning of some aspects of their behaviour. This, if accepted, increases insight.

\section{Example 3}

Sergeant and Mrs. D. both felt that in social situations they were totally unsupportive. They ignored each other whilst seeking separately group approval and approbation. Indeed they went out of their way to belittle and embarrass the partner.

The interpretation focused on "who is 'on top", by suggesting that they saw the other's weakness as evidence of their own strength. Both were consistently physically or verbally aggressive in the marriage. Perhaps because they doubted they really were strong they struggled constantly in social situations and others, to be on top. Maybe it is healthier evidence of being strong to support the weaker partner.

This later became a recurring theme in sessions, as they questioned "who is on top" in lovemaking, allowed a partner to be weak without taking advantage and thus increased mutual support.

Whilst it would be totally unrealistic to suggest everything changes with one interpretation, surveys have shown, for instance Malan et al (1975), that a single accurate interpretation in a one session assessment interview has been of lasting and significant value. It seems clear that such a useful therapeutic weapon should not be wasted by the therapist engaging in idle comments or be drawn into a frustrating three person bickering session.

\section{Conclusion}

Unhappy marriages are regrettably common. The effects may present somewhere on a spectrum from mild dissatisfaction to complete marital breakdown. Like any other pathological process, the terminal phase is reached gradually, with warning symptoms and signs and like many diseases an energetic treatment approach has hopes of success in the early stages.

There is an insidious spread in marital breakdown with involvement of more and more individuals and agencies outside the couple. Friends, relatives and neighbours are inexorably drawn in. One or both partners may develop physical or neurotic symptoms leading to medical consultation or even hospital treatment. Undesirable behaviour, violence, excess drinking, overdoses, child abuse and neglect, frequently involve the whole range of unit and welfare resources. Disciplinary offences, leading to civil or military charges are not uncommon. 
All of these added to the shared misery in the marital home, produce a picture of overwhelming disturbance and demonstrate clearly the extent and severity of the problem.

Unlike a serious physical illness within a family member, that draws a couple together, increases mutual support and can in so many ways be tackled within the family, the disordered marriage is utterly distinct. Its character is disintegration, incompatibility and total despair. Help must be from without. Conjoint marital therapy is within the scope of service doctors and all welfare agencies working within the service setting. As a treatment method it offers a real opportunity to be involved in and observe at first hand the alleviation of human misery, which is, surely, what medicine is about.

\section{Acknowledgement}

I would like to express my appreciation to Dr. E. Lewis and the staff of the Marital Unit at the Tavistock Clinic, all of whom expressed considerable interest in the problems of service life and the application of therapeutic principles to service marriages.

\section{REFERENCES}

BANCroft, J. (1975). Brit. J. med. Psychol. 48, 147.

BIRD, J. R. (1978). J roy. Army med. Cps 124

CHESTER, R. (1973). J. psychosom. Res. 17, 317.

CoOK, E. (1964). Int. J. Gr. Psychother. 14, 374

Crowe, M. J (1973). J. psychosom. Res. 17, 309

Dicks, H. V. and Stephens, J. M. (1974). In Marital and Sexual Counselling in Medical Practice.

Ed. D. Abse E Nash and L Louden Harper \& Row, Maryland.

Frances, A. and Gale, L. (1973). Fam. Pros. 12, 171

FRANKel, S. (1977). Psychiat. Quart. 49, 97

GILL, H.S. and TEMPERLEY, J. (1974). Brit. J. med. Psychol. 47, 153

Goldberg, E. M., Neill, J. Speak, B., and Faulkner, H. C. (1968). Lancet ii, 552

Greene, B. M. and Solomon, A. P. (1963). Amer. J. Psychother. 17, 443

GuRMan, A. S. (1971). Int. J. Gr. Psychother. 21, 174

Gurman, A. S. (1973a). Fam. Pros. 12, 45

Gurman, A. S. (1973b). Fam. Pros. 12, 145

HARTOG, J. (1966). Amer. J. Psychiat. 122, 1125

KoHL, D. (1962). Amer. J. Psychiat. 118, 1036

Lieberman, R. (1970). Amer J. Orthopsychiat. 40, 106

Linden, M. E., Goodwin, H. M. and Resnix, H. (1968). Int. J. Gr. Psychother. 18, 313

Malan, D. H., Sheldon Heath, E., Bacal, H. A. and Balfour, F. H. G. (1975) Arch. gen. Psychiat. 32, 110

Peck, B. B. and Schroeder, D. (1976). J. Marr. Fam. Couns. 2, 23

RePORTS OF THE ARMY Welfare INQuiry CommitTeE (1976). Chairman: Professor J. C. Spencer, H.M S.O. London.

SAGER, C. J. (1964). Int. J. Gr. Psychother. 14, 403

SAGER, C. J. (1967). Amer. J. Psychoanalysis. 27, 139

Shapiro, R. J. (1975). J. M. arr. Fam. Couns. 1, 323

SKYNNER, A. C. R. (1969). J. Child Psychol. 10, 81

Teruel, G. (1966). Brit. J. med. Psychol. 39, 231

Watson, A. S. (1963). Amer. J. Orthopsychiat. 33, 912

WaWman, R. J. (1973). J. roy. Army Med. Corps. 119, 14

Woophouse, D. (1977). Proc. roy. Soc. Med. 70, 498 